\title{
NEOTECTÔNICA DA ÁREA DO ALTO RIO PARDO (SP E MG)
}

\author{
Mário Sérgio de MELO \\ Dirceu Pagotto STEIN \\ Waldir Lopes PONÇANO \\ Carlos Alberto BISTRICHI
}

\begin{abstract}
RESUMO
A área da bacia do rio Pardo, a montante da barragem da UHE Armando de Salles Oliveira, foi analisada quanto a características indicativas de atividade neotectônica. Tais estudos, efetuados nas escalas 1:250.000 e 1:50.000, objetivaram fornecer subsídios para previsão do risco sísmico e compreensão da geomorfogênese e dinâmica atual. As características analisadas foram: distribuição dos níveis planálticos e feições morfológicas típicas (lineamentos, rupturas de declive, escarpaş rochosas, corredeiras, encostas retilíneas, leques aluviais, capturas, densidade e controle estrutural da drenagem, terraços fluviais), estruturas rúpteis (juntas, falhas) e acumulações neocenozóicas (tálus, colúvios, aluviões em planícies e terraços). A área revelou-se muito pobre em evidências de atividade neotectônica. A maioria das feições morfológicas estudadas bem como as acumulações de depósitos não mostraram padrões de distribuição que permitissem interpretações. As estruturas rúpteis, raras e de difícil análise, permitiram interpretar as principais zonas de movimentações neotectônicas quando associadas a evidências de natureza morfológica. A distribuição dos níveis planálticos e os lineamentos, ambos analisados em escala 1:250 000, revelaram-se as características mais significativas. A idade dos aplainamentos indicou atividade tectônica mais pronunciada no Paleógeno e reativações subseqüentes pouco marcadas no relevo. A correlação destas evidências com dados estruturais revelou estruturação cenozóica orientada principalmente a ENEWSW e NW-SE, refletindo propagação, muito amenizada na área, dos eventos tectônicos da faixa costeira do Sudeste do Brasil. Os procedimentos adotados destacaram a conveniência, para áreas de discreta atividade neotectônica, de análise em escala tanto regional (organização geomorfológica) quanto de detalhe (estruturas). A integração dos dados destas duas escalas de abordagem permitiu chegar às interpretações sobre a evolução neotectônica do alto rio Pardo.
\end{abstract}

\section{ABSTRACT}

The hydrographic basin of the Pardo river (São Paulo and Minas Gerais states, southeastern Brasil), upstream from the Armando de Salles Oliveira dam, has been investigated with the main purpose of recognizing regional features related to neotectonic activity. Studies of structural geology, tectonics and geomorphology carried on two different scales (1:250,000 and $1: 50,000)$ were aimed at estimating seismic risk as well as the evolution of landforms and associated erosive processes. The following topics have been specially taken into account: plateau levels, types of slopes, escarpments, lineaments, rapids, stream captures, terraces, alluvial fans, alluvial and colluvial Neocenozoic sediments, density and structural control of the drainage and brittle structures, such as joints and faults. These structures are scarce and scattered in the studied area so that structural analysis by means of classical methods could hardly be applied to the case; notwithstanding, their association to landforms, specially to the plateau, allowed an interpretation of the principal zones of neotectonic activity. Geomorphological and structural data referred to the 1:250,000 scale proved to be more useful; they indicate stronger tectonic activity in the Paleogene through the deformation of the highest plateau, followed by lesser events whose effects could not be as easily recognized through the landforms. A comparison of these results with structural data obtained from the 1:50,000 mapping displayed patterns of Cenozoic structures oriented to ENE-WSW and NW-SE, which suggests that they are the weakened effects of the tectonic activity related to the rifts of the southeastern Brasilian continental margin. 


\section{INTRODUÇÃO}

A área da bacia hidrográfica do alto rio Pardo (Fig. 1), situada na região limítrofe dos estados de São Paulo e Minas Gerais (Sudeste do Brasil), foi analisada quanto às características indicativas de atividade neotectônica. Tais estudos, efetuados nas escalas 1:250.000 e 1:50.000, foram patrocinados pelo Departamento de Engenharia Civil da CESP - Companhia Energética de São Paulo e objetivaram fornecer subsídios para o zoneamento da atividade sísmica e compreensão da geomorfogênese e dinâmica superficial atual, no interesse de usinas hidrelétricas construídas ou em projeto ao longo do rio Pardo (IPT, 1992).

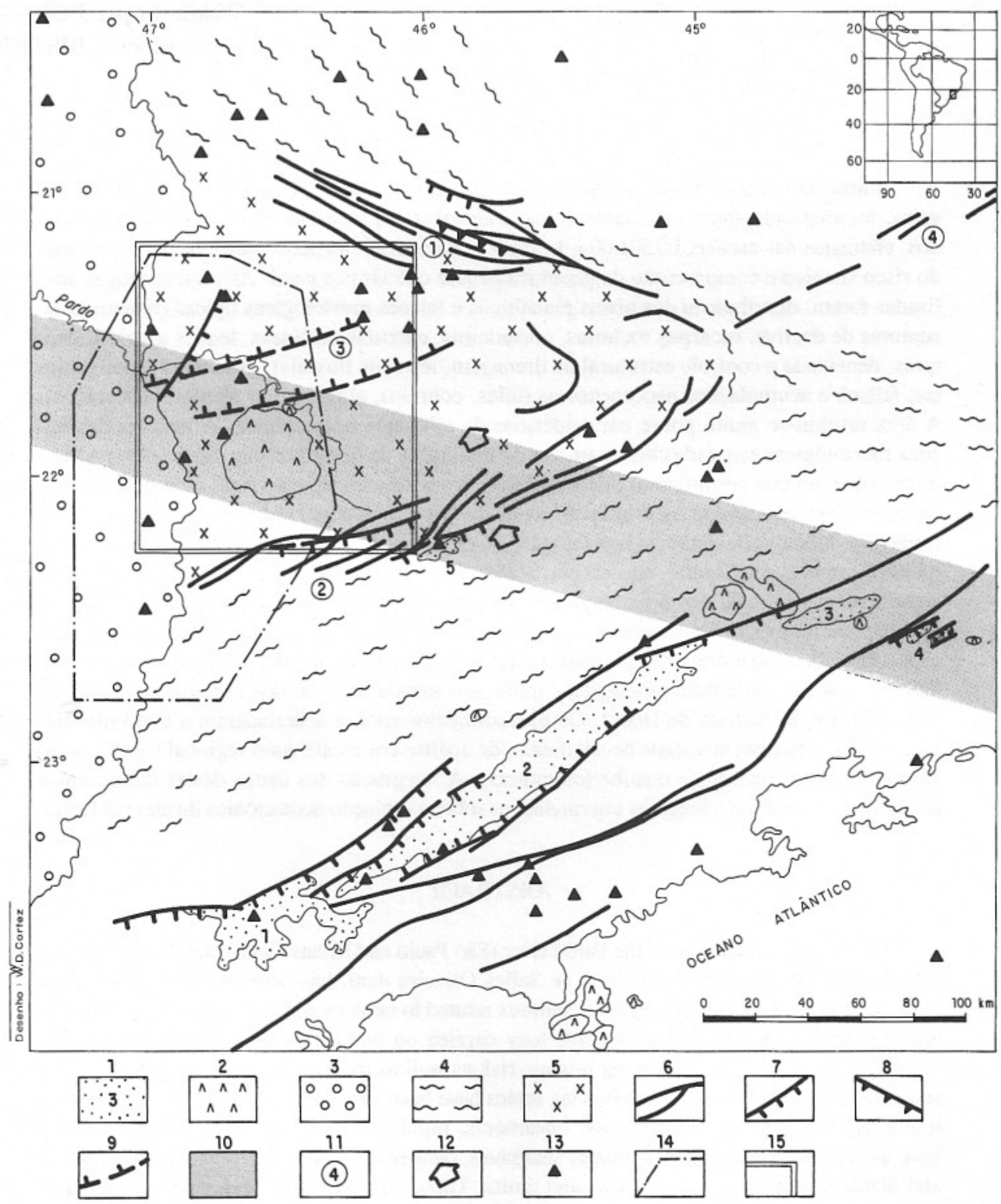

FIGURA 1 - Principais elementos tectônicos e estruturais regionais de interesse à área do alto rio Pardo; 1: bacias sedimentares terciárias ( $1=$ São Paulo, $2=$ Taubaté, $3=$ Resende, $4=$ Volta Redonda e Gráben de Casa de Pedra, 5=Pouso Alegre); 2: maciços de rochas alcalinas; 3: sedimentos e vulcânicas associadas da Bacia do Paraná; 4: faixa alto rio Grande; 5: maciço de Guaxupé; 6: falhas antigas indiscriminadas; 7: falhas mesozóicocenozóicas normais; 8: falhas mesozóico-cenozóicas inversas; 9: falhas mesozóico-cenozóicas normais interpretadas de imagens MSS; 10:lineamento sismo-tectônico de Cabo Frio (posição aproximada); 11: principais trends de falhas $(1=$ cinturão de cisalhamento de Campo do Meio; $2=$ cinturão de cisalhamento de Ouro Fino; 3 =sistema de falhas do rio Pardo; $4=$ descontinuidade crustal do alto rio Grande); 12: sentido de basculamento de blocos tectônicos; 13: epicentros de eventos sísmicos (aproximados); 14: limites da zona sismogênica de Pinhal; 15: limites da área estudada. Baseado em ALMEIDA FILHO \& PARADELLA (1977), CAVALCANTE et al. (1979), SADOWSKI \& DIAS NETO (1981), HASUI et al. (1982), RADAMBRASIL (1983), MELO et al. (1986), IPT (1989), RICCOMINI (1989), SAADI (1991) e IPT (1992). 
$\mathrm{O}$ alto rio Pardo situa-se em posição intraplaca, na Zona Sismogênica de Pinhal, com sismos históricos de intensidades máximas VI MM (Mercalli modificada), as maiores do Sudeste do Brasil. Entretanto, os dados de sismicidade monitorada são rarefeitos, não havendo definição de claros padrões de distribuição de sismos.

A existência de relevo com amplitudes expressivas, com diferentes superfícies planálticas cenozóicas desniveladas entre si em cerca de 500 metros e de densos sistemas de lineamentos morfoestruturais são argumentos adicionais da ocorrência de movimentos tectônicos cenozóicos na área do alto rio Pardo. Entretanto, as evidências diretas de atividade neotectônica não são conclusivas: superfícies de falhas são muito discretas, não se observam depressões tectônicas com depósitos neocenozóicos associados, as feições morfológicas sugestivas de falhas não chegam a definir padrões nítidos de distribuição.

Estas características geológicas - por um lado sugestivas de atividade neotectônica não desprezível na área, e por outro com rarefeitas e inconclusivas evidências diretas de tal atividade conduziram a um método de investigação compreendendo duas escalas de abordagem:

a) escala 1:250.000, abrangendo a porção da bacia hidrográfica de interesse (bacia de captação) e áreas vizinhas - distribuição dos níveis planálticos, lineamentos morfoestruturais, organização e densidade da drenagem;

b) escala 1:50.000, abrangendo a área dos empreendimentos hidrelétricos (barragens e reservatórios) - estruturas rúpteis (falhas, fraturas), feições morfológicas menores (rupturas de declive, escarpas rochosas, corredeiras, encostas retilíneas, leques aluviais, terraços fluviais, capturas e controle estrutural da drenagem).

A integração dos dados destas duas escalas de abordagem permitiu chegar às interpretações sobre a evolução neotectônica da área.

\section{CONTEXTO GEOLÓGICO REGIONAL}

A bacia hidrográfica do alto rio Pardo situase no Maciço de Guaxupé (ALMEIDA et al., 1976), constituído por terrenos antigos de alto grau metamórfico, de natureza predominantemente alóctone, bordejados por uma faixa de dobramentos mais jovem, denominada de faixa alto rio Grande (Fig. 1). Extensos cinturões de cisalhamento constituem os limites entre esta faixa de dobramentos e o Maciço de Guaxupé.

A Oeste, o maciço é recoberto por sedimentos paleozóicos e vulcânicas mesozóicas associadas da Bacia do Paraná, a qual apresenta na área limites nitidamente erosivos com direção geral $\mathrm{N}-\mathrm{S}$, e indícios de que se estendia, outrora, para Leste.
As rochas constituintes do Maciço de Guaxupé são policíclicas e polideformadas. $\mathrm{O}$ embasamento é arqueano de alto grau metamórfico, com supracrustais metavulcano-sedimentares do Proterozóico Inferior a Médio. Todas estas rochas estão afetadas por migmatização e anatexia do Proterozóico Superior e encaixam rochas granitóides intrusivas tardi a pós-tectônicas do Proterozóico Médio a Eopaleozóico.

São reconhecidas pelo menos três fases précambrianas a cambro-ordovicianas de deformação regional. A primeira, formada em regime de cisalhamento dúctil, foi responsável pela geração de persistente foliação milonítica de baixo ângulo, que condiciona importantes traços da estrutura regional. A ela se associa o sistema de cavalgamentos reconhecido na área, responsável pelo caráter alóctone e conformação em cunha do Maciço de Guaxupé.

A segunda fase foi a responsável pela formação dos cinturões de cisalhamento que delimitam o Maciço de Guaxupé, denominados Campo do Meio a norte (direção WNW-ESE) e Ouro Fino a sul (direção ENE-WSW) (CAVALCANTE et al., 1979). São de natureza transcorrente de alto ângulo e caráter dúctil-rúptil, com expressivos movimentos verticais associados. $\mathrm{O}$ cinturão de cisalhamento de Ouro Fino é subparalelo às grandes estruturas da faixa costeira do Sudeste do Brasil, representadas pela linha de costa atual, outros cinturões de cisalhamento, e pela orientação do sistema de rift da Serra do Mar (eixo de bacias sedimentares terciárias e grandes falhas normais associadas).

A terceira fase pré-cambriana a cambroordoviciana de deformação na área do Maciço de Guaxupé é representada por sistema de falhamentos transcorrentes de alto ângulo, com orientação regional NE-SW e expressiva componente vertical de movimentação. São falhas de natureza eminentemente rúptil, às quais se associam retrometamorfismo e hidrotermalismo.

Durante o Mesozóico-Paleoceno a região do alto rio Pardo foi afetada por importante magmatismo alcalino, exposto em estruturas circulares, representado por intrusivas hipoabissais e lavas efusivas, encontradas nos maciços alcalinos de Poços de Caldas e Boa Vista. Este magmatismo faz parte das manifestações associadas com o lineamento sismo-tectônico de Cabo Frio (SADOWSKI \& DIAS NETO, 1981) ou alinhamento magmático de Cabo Frio (ALMEIDA, 1991), extensa faixa tectônica de direção WNWESE (Fig. 1).

Estruturas ENE-WSW observadas em imagens MSS do satélite Landsat (ALMEIDA FILHO \& PARADELLA, 1977) indicam que a região do alto Pardo sofreu influência, ainda que atenuada, dos processos tectônicos paleogênicos 
responsáveis pela formação, na faixa costeira, do sistema de rift da Serra do Mar (ALMEIDA, 1976) ou rift continental do Sudeste do Brasil (RICCOMINI, 1989). As muitas e imponentes feições tectônicas desse sistema de rift apresentam evidências de reativações subseqüentes ao Paleógeno (ALMEIDA, 1976; MELO et al., 1986; RICCOMINI et al., 1989, entre outros).

A região não apresenta acumulações expressivas de depósitos cenozóicos. Eles aparecem como coberturas sedimentares relativamente delgadas, em ocorrências descontínuas, sendo representados principalmente por cascalhos em terraços fluviais, depósitos colúvio-aluviais, coluviões e aluviões. Usualmente apresentam localização e constituição que refletem processos de evolução morfológica regida pela epirogênese e erosão, com acumulação restrita e efêmera. Só localmente estas ocorrências apresentam possíveis relações com feições sugestivas de atividade tectônica cenozóica, mas nesses sítios não se observam associações diretas entre estruturas e sedimentação.

\section{MORFOLOGIA}

Os estudos da morfologia em escala 1:250.000 compreenderam o mapeamento da distribuição dos níveis planálticos, os lineamentos morfoestruturais e a organização e densidade da drenagem. Em escala 1:50.000 foram analisadas feições morfológicas menores.

\subsection{Níveis planálticos}

Os níveis planálticos foram interpretados em mosaicos semicontrolados de radar do Projeto Radambrasil e imagens TM (bandas 3 e 4) e MSS (bandas 5, 6 e 7) dos satélites Landsat, todas em escala 1:250.000, com o apoio de cartas topográficas em 1:250.000 e 1:50.000.

Os planaltos foram delimitados a partir de formas características de relevo; rupturas de declividade positivas e negativas de expressão regional foram o principal elemento na delimitação dos níveis planálticos.

As rupturas de declividade representam, regionalmente, a inserção de um dado nível planáltico (ou seja, de uma superfície erosiva) nas vertentes de um planalto mais elevado. A análise das variações altimétricas em cada nível planáltico completa sua caracterização.

As formas de relevo da região do alto Pardo foram organizadas em quatro níveis planálticos regionais, cada qual referido a uma superfície erosiva:

a) planaltos subnivelados pela superfície cimeira (A), a mais antiga e elevada da região, com altitude máxima de 1.764 metros; o seu caimen- to mais nítido é no sentido da antiga drenagem conseqüente (para noroeste), embora existam várias situações sugestivas de deformação por falhas; na área do maciço alcalino de Poços de Caldas os setores preservados da superfície $A$ mostram nítido controle litológico (Fig. 2);

b) planaltos subnivelados por superfície intermediária (I), cujas cotas máximas atingem 1.360 metros; seus limites ultrapassam os interflúvios regionais, e seu caimento não se prende diretamente à atual rede de drenagem; tal distribuição sugere evolução a partir de erosão relativamente antiga do nível $A$, embora algum controle tectônico seja sugerido por variações altimétricas e soleiras condicionadas por estruturas geológicas;

c) primeiro nível de planaltos rebaixados $(B)$, com nítido contorno erosivo e controle litológico, desenvolvendo-se ao longo dos principais cursos d'água em áreas de rochas cristalinas; suas cotas máximas atingem 960 metros; ultrapassa o interflúvio do rio Pardo somente num local, com a vizinha bacia do rio Grande, sugerindo ali alguma anomalia, provavelmente envolvendo captura de drenagem;

d) segundo nível de planaltos rebaixados $(B d)$, também com nítido controle erosivo e litológico, relacionando-se às calhas de drenagem, em áreas de colinas sedimentares da bacia do Paraná; suas cotas máximas atingem 800 metros.

O nível $A$ ocupa a posição da superfície Paleogênica (MARTONNE, 1940), ou Japi (ALMEIDA, 1964) ou do pediplano $\mathrm{Pd}_{3}$ (BIGARELLA \& ANDRADE, 1965), enquanto que o nível $I$ corresponderia à superfície Intermediária de MARTONNE (1940) ou ao pediplano $\mathrm{Pd}_{2}$ de BIGARELLA \& ANDRADE (1965), não havendo evidências que comprovem ser um simples rebaixamento tectônico do nível $A$, conforme postularam FREITAS (1951) e ALMEIDA (1964). Os níveis $B$ e $B d$ situam-se na posição da superfície Neogênica de MARTONNE (1940) ou pediplano $\mathrm{Pd}_{1}$ de BIGARELLA \& ANDRADE (op. cit.), embora constituam dois níveis distintos, cujas relações não puderam ser aprofundadas.

Restos da antiga superfície fóssil Itaguá (ALMEIDA, 1964) também foram reconhecidos a leste dos sedimentos da Bacia do Paraná, embora muito desfigurada, confundindo-se com o primeiro nível de planaltos rebaixados.

Na Fig. 2 estão representados os limites dos planaltos subnivelados pela superfície cimeira (nível $A$ ). As principais situações sugestivas de deformação por falhas, estas principalmente de caráter normal, são:

a) a noroeste e oeste de Poços de Caldas setores de planalto com limites estreitamente relacionados a estruturas; 
b) presença de assimetrias de drenagem e escarpas rochosas verticais nos limites do nível $A$ junto à estrutura N-S que passa por Poços de Caldas e às estruturas ENE-WSW que passam a sudoeste de Caconde; c) aparente basculamento para nordeste de blocos escalonados por estruturas de direção NW-SE, a sudoeste de Poços de Caldas;

d) setores de planalto com limites relacionados a estruturas geológicas no extremo sul da área.

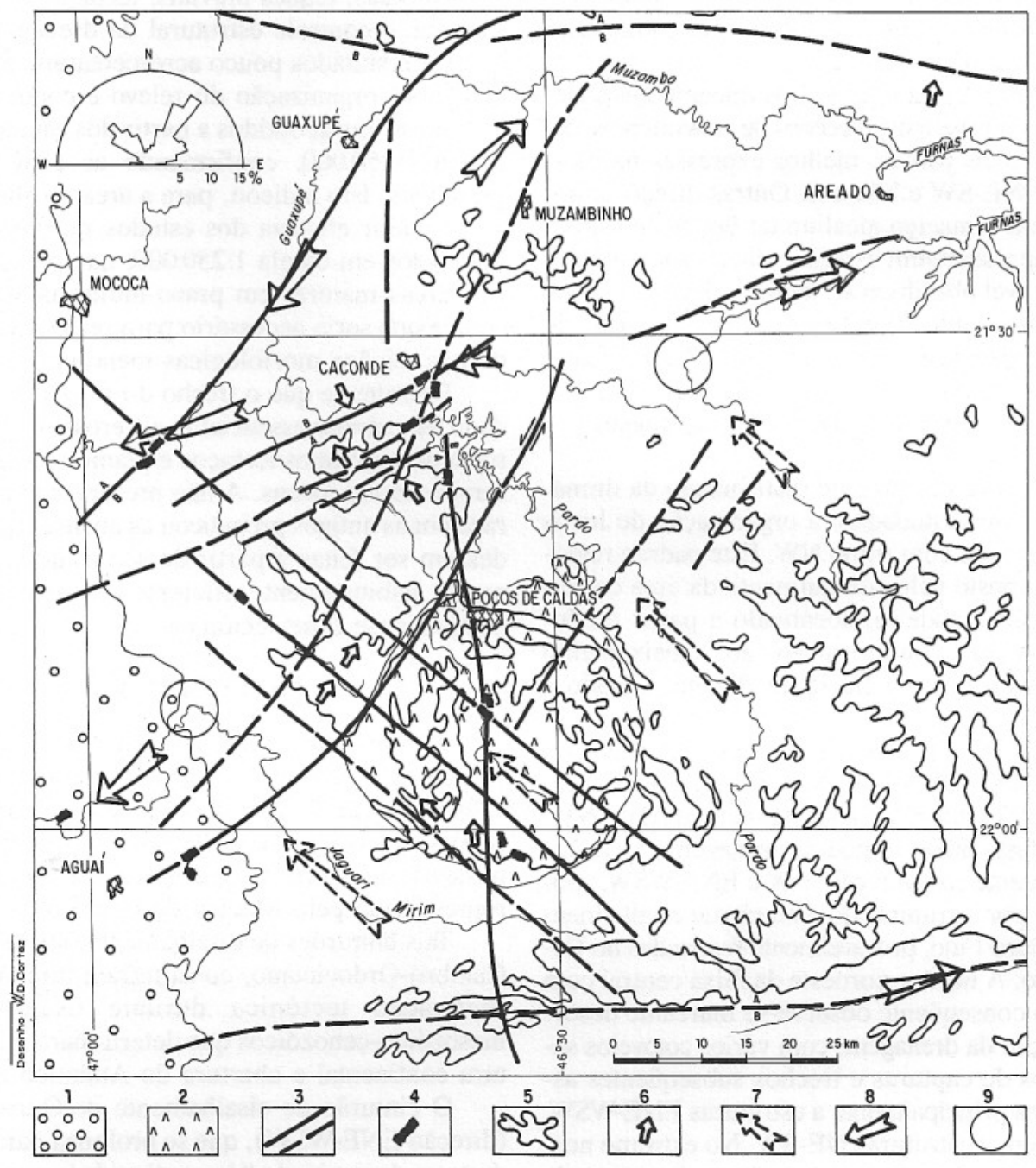

FIGURA 2 - Elementos morfológicos e tectônicos da área do alto rio Pardo; 1: sedimentos e vulcânicas associadas da Bacia do Paraná; 2: maciços alcalinos de Poços de Caldas e Boa Vista; 3: principais estruturas reativadas no Mesozóico-Cenozóico; 4: evidências de campo de falhas mesozóico-cenozóicas; 5: limite do nível planáltico associado à superfície cimeira $(A) ; 6$ : caimento dos níveis planálticos; 7: drenagem conseqüente; 8: drenagem subseqüente; 9: prováveis capturas de drenagem. A rosácea no canto superior esquerdo corresponde aos somatórios dos comprimentos dos lineamentos morfoestruturais extraídos de imagens TM do satélite Landsat 5, distribuídos por intervalo de $10^{\circ}$.

\subsection{Lineamentos morfoestruturais}

Os lineamentos morfoestruturais foram extraídos de imagens TM do satélite Landsat 5 e mosaicos de radar do Projeto Radambrasil, ambos em escala 1:250.000.

Os principais feixes de lineamentos definem as estruturas representadas na Fig. 2. Em parte eles refletem grandes estruturas antigas, como é o caso das direções E-W a ENE-WSW, correspondentes ao cinturão de cisalhamento de Ouro Fino, e da direção WNW-ESE, correspondente ao cinturão de cisalhamento de Campo do Meio.

Estruturas antigas menos importantes, como os falhamentos transcorrentes com orientação NESW, também se encontram bem expressos nos lineamentos. Esta é a principal direção de concentração de lineamentos na área (rosácea da Fig. 2). 
Outros feixes de lineamentos morfoestruturais aparecem, de direção N-S e NW-SE, esta última correspondendo à segunda maior concentração de lineamentos na área. Sua origem deve ser buscada preferencialmente em movimentos tectônicos mais recentes (terciários), embora em parte correspondam a estruturas pré-cambrianas menos importantes.

A freqüência relativa dos lineamentos sugere as duas principais direções de movimentos tectônicos mais jovens, melhor expressas na morfologia NE-SW e NW-SE. Outras direções, por cortarem o maciço alcalino de Poços de Caldas e por apresentarem estreita relação com os limites do nível planáltico $\mathrm{A}$, também devem ser consideradas como direções de movimentação de idade cenozóica. São elas: N-S e ENE-WSW.

\subsection{Organização e densidade da drenagem}

O padrão normal de distribuição da drenagem na área estudada é a organização de leitos conseqüentes com rumo NW. Este padrão regional é imposto pelo soerguimento da área costeira situada a sudeste, acentuado a partir do Jurássico, em contraposição ao rebaixamento relativo do eixo da Bacia do Paraná, situado a noroeste.

Na Fig. 2 observa-se faixa central orientada segundo NE-SW onde os principais rios seguem este padrão normal conseqüente com rumo NW. A sul desta faixa, impõe-se drenagem de caráter subseqüente com direção E-W a ENE-WSW, controlada por estruturas do cinturão de cisalhamento de Ouro Fino, provavelmente reativadas no Cenozóico. A norte e noroeste da faixa central com padrão conseqüente observa-se marcante desorganização da drenagem, com vários cotovelos sugestivos de capturas e trechos subseqüentes associados principalmente a estruturas ENE-WSW, e também a estruturas NE-SW. No extremo norte da área a drenagem subseqüente é controlada por estruturas WNW-ESE do cinturão de cisalhamento de Campo do Meio.

O estudo de densidade de drenagem na área foi realizado a partir de cartas topográficas em escala 1:50.000, para integração de resultados em escala 1:250.000. A metodologia e resultados alcançados estão apresentados em PONÇANO \& HIRUMA (s.d.)

As principais anomalias de adensamento da drenagem apresentam estreita correlação com blocos topograficamente soerguidos delimitados por estruturas E-W, ENE-WSW, NE-SW e N-S, sugerindo rejuvenescimento do relevo ao longo dessas direções. As principais anomalias de rarefação da drenagem correspondem às formações sedimentares da Bacia do Paraná, no limite oeste da área estudada.
3.4 Feições morfológicas estudadas em escala 1:50.000

Foram estudadas nesta escala as rupturas de declive, escarpas rochosas, corredeiras, encostas retilíneas, leques aluviais, terraços fluviais, capturas e controle estrutural da drenagem.

Os resultados pouco acrescentaram aos dados sobre organização do relevo e condicionamento estrutural obtidos a partir dos estudos em escala 1:250.000, confirmando as conclusões principais. Isto indicou, para a área do alto Pardo, a maior eficácia dos estudos morfológicos realizados em escala 1:250.000, que podem cobrir áreas maiores em prazo muito menor que aquele que seria necessário para realizar o estudo das feições morfológicas menores.

Ressalte-se que o trecho do rio Pardo estudado tem caráter essencialmente erosivo, com raros e descontínuos terraços e planícies aluviais, sempre muito jovens. A não preservação de terraços mais antigos prejudicou as análises que pudessem ser feitas a partir de seu estudo, ferramenta habitualmente eficiente em estudos de morfogênese e neotectônica.

\section{ESTRUTURAS}

As mais marcantes estruturas da região estudada são representadas pelos cinturões de cisalhamento de Campo do Meio e de Ouro Fino (CAVALCANTE et al., 1979), que delimitam a norte e a sul, respectivamente, a cunha tectônica representada pelo Maciço de Guaxupé.

Tais cinturões de cisalhamento, ativos até o Cambro-Ordoviciano, constituíram direções de reativação tectônica durante os eventos mesozóico-cenozóicos que determinaram a ruptura continental e abertura do Atlântico Sul.

O cinturão de cisalhamento de Ouro Fino (direção ENE-WSW), que se prolonga para nordeste na denominada "descontinuidade crustal do alto rio Grande" (SAADI, 1991; SAADI, 1993), é paralelo às principais estruturas do Sudeste do Brasil. Sobre ele são interpretadas falhas normais reativadas (ALMEIDA FILHO \& PARADELLA, 1977) e ainda descritas falhas normais e um gráben neocenozóico na área de Pouso Alegre (SAADI, 1991, Fig. 1). Este último autor reitera ainda os basculamentos de blocos tectônicos para noroeste, fato já há muito indicado pelos geomorfólogos (v.g. MARTONNE, 1940).

O cinturão de cisalhamento de Campo do Meio apresenta evidências de reativação tanto como falha normal quanto como falha inversa (CAVALCANTE et al., 1979).

ALMEIDA FILHO \& PARADELLA (1977) interpretam várias estruturas na área do alto Pardo, a partir de imagens MSS. Destacam estrutu- 
ras de direção ENE-WSW, algumas delas assinaladas como falhas normais, e sugerem que a região constitua uma zona de fraqueza orientada nesta direção, cuja origem poderia estar relacionada com os eventos que criaram a Serra da Mantiqueira e a Bacia de Taubaté. Estudos de campo de detalhe na área de Caconde confirmaram uma dessas estruturas, que compõe o denominado "sistema de falhas do Rio Pardo" (OLIVEIRA et al., 1989).

Outra estrutura regional, de menor destaque, é representada pela Falha de Guaxupé, de direção NNE-SSW, assinalada por CAVALCANTE et al. (1979), a qual foi em parte confirmada em levantamentos de campo de detalhe (OLIVEIRA et al., 1983). CAVALCANTE et al. (1979) associam a Falha de Guaxupé a esforços tensionais, sem lhes atribuir a origem.

A área do alto Pardo destaca-se ainda por se situar sobre o "lineamento sismo-tectônico de Cabo Frio", definido por SADOWSKI \& DIAS NETO (1981) como sendo uma faixa de intenso magmatismo alcalino mesozóico e com relativa concentração da atividade sísmica atual. Tal lineamento é correlacionado a estruturas da borda continental submersa e da plataforma continental (zona de fratura do Rio de Janeiro de ASMUS, 1978). Mais recentemente, ALMEIDA (1991) destaca o caráter magmático dessa faixa estrutural, denominando-a "Alinhamento Magmático de Cabo Frio".

\section{NEOTECTÔNICA}

Durante os levantamentos de dados estruturais de campo, foram realizados reconhecimentos ao longo das estruturas regionais (escala 1:250.000) e investigada sistematicamente a área imediata de interesse às barragens e reservatórios do alto rio Pardo (escala 1:50.000). Buscouse nesses levantamentos reconhecer as estruturas rúpteis (falhas, fraturas) indicativas de deformações tectônicas relativamente recentes. Esta tarefa foi prejudicada pela deformação policíclica exibida pelas rochas, dificultando distinguir as estruturas mais novas. $\mathrm{Na}$ análise final dos dados foram consideradas somente as falhas, pois os dados de fraturas não produziram interpretações significativas.

Foram encontradas raras estruturas atribuídas a movimentos tectônicos relativamente recentes (mesozóico-cenozóicos) na área. Elas aparecem em somente uma dezena (Fig. 2) de um total de cerca de 700 afloramentos estudados. Estas estruturas são representadas por discretas superfícies de falha com estrias de atrito. Quando cortam rochas do embasamento, ocasionalmente exibem faixas brechadas decimétricas associadas ou preenchimento centimétrico de argilas esmectí- ticas, interpretadas como transformação de rocha cominuída.

Quando cortam diabásios de sills da Bacia do Paraná, podem apresentar delgadas lâminas de minerais de origem hidrotermal (carbonatos, argilas esmectíticas, pirita, pirrotita), as quais também se apresentam estriadas, indicando movimentação posterior ao hidrotermalismo.

Os dados de ocorrência destas superfícies de falha estriadas, integrados com evidências morfológicas (lineamentos, escarpamentos, limites dos níveis planálticos, alinhamentos de drenagem), permitiram interpretar os principais alinhamentos estruturais representados na Fig. 2. Eles não se apresentam no terreno como marcantes linhas de falhas. Antes, constituem direções preferenciais de ocorrência das superfícies de falha de escala métrica e de adensamento de fraturas, ocasionalmente originando brechas.

As superfícies de falhas estriadas, separadas de acordo com as unidades litoestratigráficas cortadas, estão apresentadas na Fig. 3. Os dados mostram variação na orientação das superfícies, na posição das estrias de atrito, bem como na natureza das falhas (normais, inversas, sinistrais, dextrais). Entretanto, a orientação das superfícies de falhas corrobora as principais direções estruturais reconhecidas regionalmente: ENEWSW, NE-SW, N-S e NW-SE. Não foram encontradas nos levantamentos ora realizados na área evidências de campo de reativação dos cinturões de cisalhamento de Ouro Fino e Campo do Meio, apesar de elas serem citadas em outros estudos.

A dispersão, rarefação e inconsistência dos dados não permitiram aplicar os métodos clássicos de análise estrutural para definição da cinemática e fases de deformação atuantes na região. Assim sendo, a interpretação da evolução tectônica mesozóico-cenozóica da área baseou-se na integração dos dados morfológicos e estruturais obtidos nos levantamentos em escala regional e de detalhe, além de levar em conta os modelos tectônicos preexistentes.

A sucessão de eventos que pode ser interpretada com base na metodologia adotada e nos dados disponíveis é a seguinte:

a) desenvolvimento de zona de cisalhamento simples (rotacional) com magmatismo associado, orientada segundo WNW-ESE, correspondente ao lineamento sismo-tectônico de Cabo Frio, a partir do Cretáceo Superior; admite-se caráter dextral para tal zona de cisalhamento, a exemplo do que foi proposto para a região da $\mathrm{Ba}-$ cia de Resende (MELO, 1985), ela geraria um sistema de discretas estruturas, de acordo com o modelo de Riedel e outros dele derivados (apud SADOWSKI, 1983), que comporiam o sistema de falhas, ou zonas preferenciais de movi- 


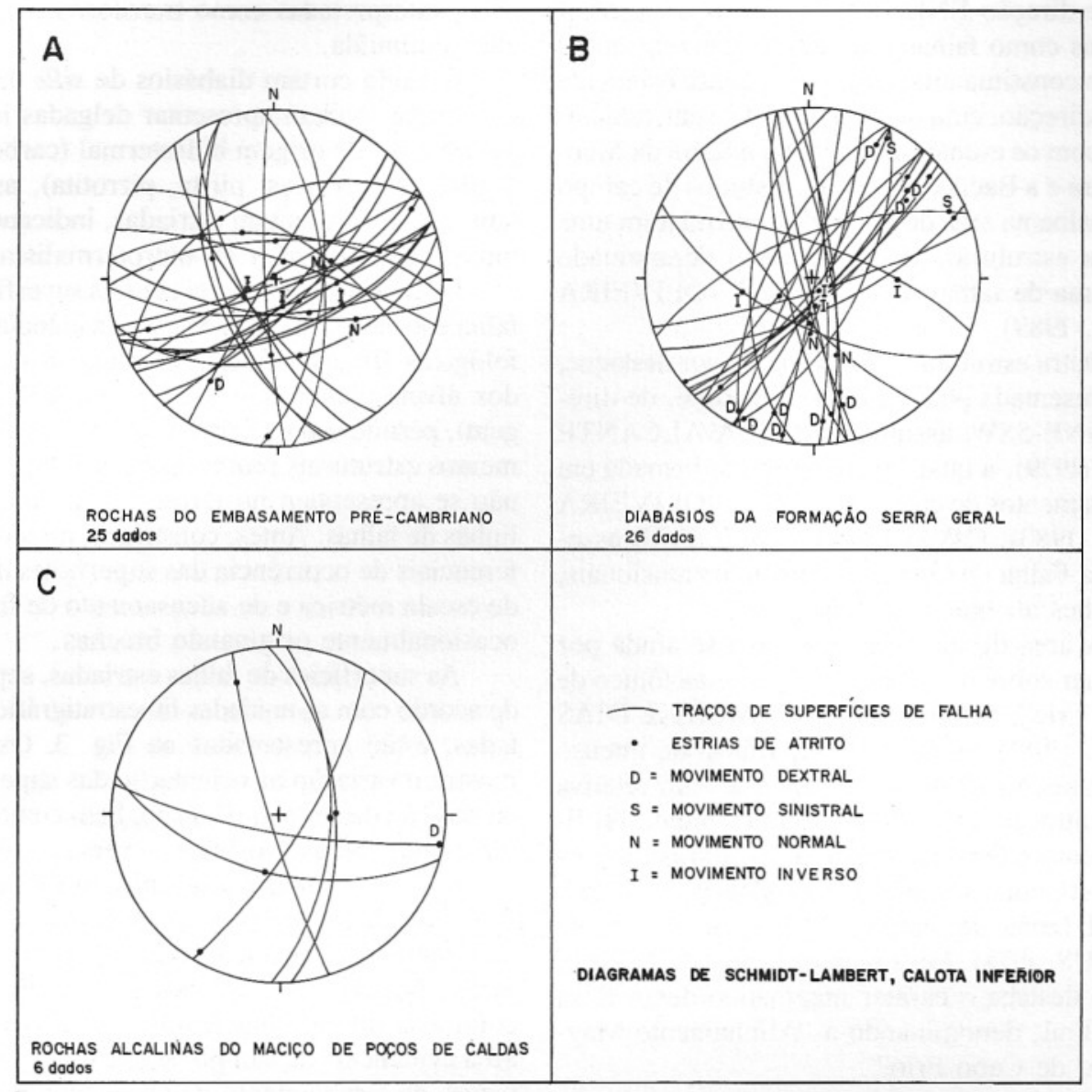

FIGURA 3 - Dados de superfícies de falhas com estrias de atrito; A: rochas do embasamento pré-cambriano; B: diabásios da Formação Serra Geral da Bacia do Paraná (Jurássico-Cretáceo); C: rochas alcalinas do maciço de Poços de Caldas (Cretáceo-Paleoceno). Diagrama Schmidt-Lambert, calota inferior.

mentação, com componente horizontal de movimento predominante: estruturas NE-SW (fraturas $X$ dos modelos derivados de Riedel), estruturas N-S (fraturas $R^{1}$ de Riedel) e estruturas NW-SE (fraturas $R$ de Riedel); as direções destas estruturas foram em parte influenciadas por falhas antigas, principalmẹente aquelas de direção NE-SW;

b) distensão NNW-SSE no Paleógeno (Eoceno-Oligoceno), reativando antigas estruturas dos cinturões de cisalhamento de Ouro Fino e Campo do Meio e, principalmente, originando novas estruturas de direção ENE-WSW, entre elas o sistema de falhas do rio Pardo; estas estruturas não se restringem à área de influência do lineamento sismo-tectônico de Cabo Frio, estendendo-se para nordeste à vizinha bacia hidrográfica do alto rio Grande (reservatório de Furnas); esta fase está bem representada sobretudo nos afloramentos de rochas do embasamento cristalino (Fig. 3-A), onde a componente vertical de movimentação é dominante; deve ter rea- tivado estruturas dos cinturões de cisalhamento de Ouro Fino (E-W) e Campo do Meio (WNWESE), bem como estruturas N-S e NE-SW da fase precedente;

c) retomada, após o Paleógeno (até o Quaternário?), do cisalhamento simples dextral WNW-ESE antes mencionado; nesta fase, parte das superfícies de falhas ENE-WSW pode ter sido reativada como falhas inversas (Fig. 3-A).

A atividade mais antiga (pré-Paleógeno) ao longo do lineamento sismo-tectônico de Cabo Frio, a par da atividade magmática, estaria relacionada com o hidrotermalismo observado sobretudo nas superfícies de falha em diabásios (Fig. 3-B). A origem deste lineamento estaria associada a esforços intraplacas gerados pela rotação dos continentes (SADOWSKI \& DIAS NETO, 1981; MELO, 1985).

A distensão NNW-SSE no Paleógeno estaria associada aos imponentes eventos da borda continental, que geraram as bacias do sistema de rift da Serra do Mar (ALMEIDA, 1976), e as 
grandes escarpas representadas pelas serras do Mar e da Mantiqueira. Esta distensão estaria associada a decaimento termal em zona de anomalia do manto no Sudeste do Brasil, manifestada durante a ruptura continental, no Mesozóico (CHANG \& KOWSMANN, 1984).

A magnitude dos deslocamentos de blocos gerados nesta fase decai progressivamente em direção ao interior do continente. $\mathrm{Na}$ área do alto Pardo, com base nos desníveis topográficos atuais e distribuição dos níveis planálticos, estima-se que os desnivelamentos não tenham alcançado uma centena de metros, como se observa nos blocos escalonados por estruturas ENE-WSW a sudoeste de Caconde.

Embora muito inferior à cifra dos abatimentos conhecidos na borda continental (mais de mil metros), estes desnivelamentos são os maiores que se pode inferir na área do alto Pardo, exercendo importante controle na organização da drenagem. Estima-se que os desnivelamentos da superfície cimeira $(A)$ por estruturas NW-SE (ligadas ao cisalhamento simples dextral) sejam ainda menores, não ultrapassando poucas dezenas de metros.

A retomada do cisalhamento simples dextral WNW-ESE após o Paleógeno corresponde, na verdade, ao prosseguimento da atividade ao longo da extensa faixa de fraqueza estrutural representada pelo lineamento sismo-tectônico de Cabo Frio, temporariamente sobrepujada pela intensa atividade da borda continental, sob esforços distensivos. Embora atividade magmática póspaleogênica seja conhecida na extremidade costeira do lineamento, na região do alto Pardo ela não é conhecida e o hidrotermalismo também deve ter arrefecido.

A atividade sísmica atual na região que abrange o alto rio Pardo levou à definição da Zona Sismogênica de Pinhal (IPT, 1989), caracterizada pela ocorrência de sismos com intensidade máxima até VI MM (escala Mercalli modificada), uma das mais ativas do Sudeste do Brasil. Os limites da Zona Sismogênica de Pinhal (Fig. 1), bem como os epicentros e isossistas de seus principais sismos, apresentam forte relação com a região de cruzamento de três direções estruturais regionais:

a) a extremidade leste do cinturão de cisalhamento de Ouro Fino e do sistema de falhas do rio Pardo, ambos com direção ENE-WSW;

b) o lineamento sismo-tectônico de Cabo Frio, com direção WNW-ESE;

c) o limite erosivo da Bacia do Paraná, com direção geral N-S.

Assim, a atividade neotectônica na área do alto Pardo, com reflexos na sismicidade atual da região, provavelmente é controlada por estas três direções estruturais, ainda que elas apresentem natureza e idades diferentes. A concentração de estruturas e de sismos recentes junto ao limite erosivo da Bacia do Paraná sugere possível efeito cumulativo de esforços cisalhantes e compensação isostática (isostatic rebound), esta associada à remoção, por erosão diferencial, de expressivos volumes de sedimentos que antes jaziam sobre as exposições atuais de rochas do embasamento.

Cabe destacar ainda a relativa concentração de sismos ao longo dos prolongamentos, para além dos limites da Zona Sismogênica de Pinhal, do sistema de falhas do rio Pardo e do lineamento sismo-tectônico de Cabo Frio. Neste, a concentração de sismos é mais nítida na faixa costeira, a leste dos limites da Fig. 1.

Entre as bacias terciárias de Taubaté e São Paulo observa-se outra concentração de sismos na faixa costeira, alinhada segundo WNW-ESE, paralela ao lineamento sismo-tectônico de Cabo Frio. Esta faixa corresponde aproximadamente à porção costeira do "alinhamento estrutural do Tietê" (COIMBRA et al., 1977), cuja atividade tectônica supostamente se estenderia do PréCambriano ao Quaternário.

Estas estruturas, bem como outras de direção WNW-ESE que cortam o Sudeste do Brasil, como o "alinhamento estrutural do Paranapanema" (FÚLFARO, 1974), parecem configurar um padrão de deformação regional com influência na atividade sísmica, cuja origem ainda não se encontra satisfatoriamente explicada.

\section{CONCLUSÕES}

A área da bacia hidrográfica do alto rio Pardo, situada em posição intraplaca, apresenta marcante caráter erosivo, com raras acumulações de depósitos cenozóicos, prejudicando a análise da atividade neotectônica a partir de dados estratigráficos. Por outro lado, as deformações neotectônicas são relativamente discretas, e as estruturas a elas associadas cortando as rochas da região são muito difíceis de serem encontradas.

Assim sendo, a análise da atividade neotectônica baseou-se em estudos morfológicos em escala 1:250.000, compreendendo o mapeamento da distribuição de níveis planálticos, os lineamentos morfoestruturais e a organização e densidade da drenagem, além de estudos em escala 1:50.000, compreendendo as estruturas rúpteis e feições morfológicas menores (rupturas de declive, escarpas rochosas, corredeiras, encostas retilíneas, leques aluvais, capturas e controle estrutural da drenagem).

Foram identificados quatro níveis planálti$\cos$ regionais, denominados $A$ (alto), $I$ (intermediário), $B$ (primeiro nível rebaixado) e $B d$ (segundo nível rebaixado). A superfície cimeira, que 
define o nível $A$ (paleogênico), apresenta várias situações sugestivas de deformação por falhas. A superfície $I$ tem limites erosivos, com controle litológico e localmente com sugestões de controle tectônico. As superfícies $B$ e $B d$ (neogênicas) mostram limites nitidamente erosivos.

Os lineamentos morfoestruturais concentram-se em feixes que refletem antigas estruturas pré-cambrianas, em parte reativadas, e também estruturas mais novas. As principais direções estruturais marcadas pelos lineamentos são: E-W, WNW-ESE, ENE-WSW, NE-SW, N-S e NW-SE.

A drenagem regional conseqüente organizase no rumo noroeste e é marcadamente desorganizada em faixa de ocorrência de estruturas ENEWSW e secundariamente NE-SW, onde apresenta sinais de capturas e leitos subseqüentes encaixados nestas direções. Drenagens subseqüentes também são observadas em importantes estruturas pré-cambrianas, possivelmente reativadas.

Anomalias de adensamento da drenagem apresentam estreita correlação com as estruturas E-W, ENE-WSW, NE-SW e N-S. Anomalias de rarefação correspondem às formações sedimentares da Bacia do Paraná.

O estudo das feições morfológicas menores (rupturas de declive, escarpas rochosas, corredeiras, encostas retilíneas, leques aluvais, capturas e controle estrutural da drenagem) pouco acrescentou em relação às conclusões baseadas nos dados regionais, indicando maior eficácia dos estudos geomorfológicos realizados em escala 1:250.000, apoiados por investigações estruturais de campo orientadas para áreas críticas.

Os dados de estruturas rúpteis, representados por raras superfícies estriadas de falhas, corroboram as principais direções estruturais reconhecidas regionalmente. Entretanto, apresentam variações na posição das estrias de atrito e na natureza das falhas, dificultando a aplicação de métodos usuais de análise estrutural.

Com base na integração dos dados geológicos e geomorfológicos obtidos em escala regional (1:250.000) e de detalhe (1:50.000) interpretouse a ocorrência de três fases principais de eventos tectônicos mesozóico-cenozóicos significativos para a análise da atividade neotectônica na área:

a) desenvolvimento, a partir do Cretáceo Superior, de zona de cisalhamento simples dextral orientada segundo WNW-ESE, correspondente ao lineamento sismo-tectônico de Cabo Frio; as estruturas NE-SW, N-S e NW-SE estariam associadas a este evento;

b) distensão NNW-SSE no Paleógeno (Eoceno-Oligoceno), associada aos eventos geradores do sistema de rift da Serra do Mar na borda continental; as estruturas ENE-WSW estariam associadas a esta fase;

c) prosseguimento da atividade (após o Paleógeno) ao longo do lineamento sismo-tectônico de Cabo Frio; esta fase seria a responsável pelos esforços neotectônicos na área do alto Pardo, dissipados ao longo do sistema de estruturas desenvolvido previamente.

A concentração de estruturas reativadas e de sismos atuais na região de cruzamento do lineamento sismo-tectônico de Cabo Frio (WNWESE) com o cinturão de cisalhamento de Ouro Fino e o sistema de falhas do rio Pardo (ENEWSW) sobre o limite erosivo da Bacia do Paraná (N-S) sugere controle destas três direções estruturais regionais na ativid@de neotectônica e sismicidade atual do alto rio Pardo. Esta aparente relação de estruturas rúpteis com a borda erosiva da Bacia do Paraná sugere a possibilidade de efeito cumulativo de discretos movimentos verticais, associados a compensação isostática pela remoção de sedimentos.

\section{REFERÊNCIAS BIBLIOGRÁFICAS}

ALMEIDA, F.F.M. de. 1964. Fundamentos geológicos do relevo paulista. São Paulo: Instituto Geográfico e Geológico. p.169-263. (Boletim 41).

1976. The system of continental rifts bordering the Santos Basin. An. Acad. bras. Ciênc., v.48 (supl.), p.13-26.

1991. O alinhamento magmático de Cabo Frio. In: SIMPÓSIO DE GEOLOGIA DO SUDESTE, 2, 1991, São Paulo. Atas... São Paulo: SBG/NSP-RJ. p.423-428.
ALMEIDA, F.F.M. de, HASUI, Y., NEVES, B.B. de B. 1976. The upper Precambrian of South America. Bol. IG-USP, v. 7, p. 45-80.

ALMEIDA FILHO, R. \& PARADELLA, W.R. 1977. Estudo do maciço alcalino de Poços de Caldas através de imagens LANDSAT com ênfase em mineralizações radioativas. São José dos Campos: INPE. 130p. (Relatório $11 / 2-$ TPT/065).

ASMUS, H.E. 1978. Hipóteses sobre a origem dos sistemas de zonas de fraturas oceânicas/alinhamentos continentais que ocorrem 
nas regiões sudeste e sul do Brasil. In: PETROBRÁS. Aspectos estruturais da margem leste e sudeste do Brasil. Rio de Janeiro: PETROBRÁS/CENPES/DINTEP. p.39-73. (Série projeto REMAC, 4).

BIGARELLA, J.J. \& ANDRADE, G.O. de. 1965. Contribution to the study of the Brazilian Quaternary. In: WRIGHT JR., H.E., FREY, D.G. (Eds.) International studies on the Quaternary. New York: Geological Society of America. p. 443-451.

CAVALCANTE, J.C., CUNHA, H.C.S., CHIEREGATTI, L.A., KAEFER, L.Q., ROCHA, J.M. de, DAITX, E.C., COUTINHO, M.G.N., YAMAMOTO, K., DRUMOND, J.B.V., ROSA, D.B., RAMALHO, R. 1979. Projeto Sapucaí. Relatório final de Geologia. Brasília, DNPM. 299p. (Série Geologia, 5. Seção Geologia Básica, 2).

CHANG, H.K. \& KOWSMANN, R.O. 1988. Subsidência térmica e espessura crustal da Bacia de Santos. In: CONGRESSO BRASILEIRO DE GEOLOGIA, 33, Rio de Janeiro, 1984. Anais... Rio de Janeiro: SBG/NRJ. v.4, p.1602-1614.

COIMBRA, A.M., BRANDT NETO, M., PETRI, S. 1977. O alinhamento estrutural do Tietê. In: SIMPÓSIO DE GEOLOGIA REGIONAL, 1, 1977, São Paulo. Atas... São Paulo, SBG/NSP, p. 145-152.

FREITAS, R.O. de. 1951. Ensaio sobre a tectônica moderna do Brasil. São Paulo: Fac. Fil. Ciên. Let. USP. 120p. (Bol. Geol., 6)

FÚLFARO, V.J. 1974. Tectônica do alinhamento estrutural do Paranapanema. Bol. IG, n. 5, p.129-138.

HASUI, Y., ALMEIDA, F.F.M. de, MIOTO, J.A., MELO, M.S. de. 1982. Geologia, tectônica, geomorfologia e sismologia regionais de interesse às usinas nucleares $d a$ praia de Itaorna. São Paulo: IPT, 149p. (Publicação IPT, 1225) (Série Monografias, 7).

INSTITUTO DE PESQUISAS TECNOLÓGICAS DO ESTADO DE SÃO PAULO S.A. - IPT. 1989. Compartimentação estrutural e evolução tectônica do Estado de São Paulo. São Paulo, 289 p. (IPT. Relatório 27.394).

1992. Sismotectônica e dinâmica superficial na área do alto rio Pardo (SP e $M G$ ). São Paulo: IPT. (IPT. Relatório 30.074).
MARTONNE, E. de. 1940. Problèmes morphologiques du Brésil tropical atlantique. Ann. de Géographie, Paris, an 49, n.277, p.1-27, e n.278-279, p.106-129.

MELO, M.S. de. 1985. Estruturas da área da Bacia de Resende (RJ) e os modelos tectônicos regionais. In: SIMPÓSIO REGIONAL DE GEOLOGIA, 5, 1985, São Paulo. Atas... São Paulo: SBG/NSP. v.1, p.323-336.

CAETANO, S.L.V., COIMBRA, A.M. 1986. Tectônica e sedimentação na área das bacias de São Paulo e Taubaté. In: CONGRESSO BRASILEIRO DE GEOLOGIA, 34, 1986, Goiânia. Anais... Goiânia: SBG. v.1, p.321-336.

OLIVEIRA, M.A.F. de, FRANCESCONI, R., CORDEIRO, C.M., INGLEZ, A.G., OLIVEIRA, E.G., SENA, C.A.S. 1983. Geologia da porção paulista das quadrículas Caconde e Guaxupé. In: JORNADA DA CARTA GEOLÓGICA DO ESTADO DE SÃO PAULO EM 1:50.000, 1, 1983, São Paulo. Atas... São Paulo: PRÓ-MINÉRIO. p. $171-188$.

OLIVEIRA, M.A.F. de, MORALES, N., ZANARDO, A., CARVALHO, S.G. de, MANIAKAS, S. 1989. Projeto: mapeamento geológico em 1:25.000 do quadrante noroeste da Folha Caconde; relatório final. UNESP - PRÓ-MINÉRIO. Rio Claro: UNESP - PRÓ-MINÉRIO. 170p.

PONÇANO, W.L. \& HIRUMA, S. s.d. Densidade de drenagem e sua relação com fatores geomorfopedológicos na bacia do alto rio Pardo, SP e MG (no prelo).

RADAMBRASIL. 1983. SECRETARIA GERAL - Ministério de Minas e Energia. Projeto RADAMBRASIL; folhas SF.23/24, Rio de Janeiro/Vitória; pedologia, geomorfologia, 1:1000.000. Rio de Janeiro. (Levantamento de Recursos Naturais).

RICCOMINI, C. 1989. O rift continental do Sudeste do Brasil. São Paulo. 256p. (Tese de Doutoramento, IGUSP)

PELOGGIA, A.V.G., SALONI, J.C.L., KOHNKE, M.W., FIGUEIRA, R.M. 1989. Neotectonic activity in the Serra do Mar rift system (southeastern Brazil). J. S. Am Earth Sci., v.2, p.191-197.

SAADI, A. 1991. Ensaio sobre a morfotectônica de Minas Gerais: tensões intra-placa, descontinuidades crustais e morfogênese. Belo Horizonte. 285p. (Tese para o cargo de Professor Titular. Depto. de Geografia, 
SAADI, A. 1993. Neotectônica da Plataforma Brasileira: esboço e interpretação preliminares. Geonomos, Rev. de Geociências da UFMG. Belo Horizonte. v.1, n.1, p.1-15.

SADOWSKI, G.R. 1983. Sobre a geologia estrutural de cinturões de cisalhamento conti- nentais. São Paulo, 108p. (Tese de Livre Docência, Instituto de Geociências da Universidade de São Paulo).

SADOWSKI, G.R. \& DIAS NETO, C.M. 1981. O lineamento sismo-tectônico de Cabo Frio. Rev. Bras. Geoc., v.11, n.4, p.209-212.

Trabalho realizado com apoio da CESP - Companhia Energética de São Paulo S.A.

Endereço dos autores:

Mário Sérgio de Melo, Dirceu Pagotto Stein, Waldir Lopes Ponçano e Carlos Alberto Bistrichi - Instituto de Pesquisas Tecnológicas do Estado de São Paulo S/A - Cidade Universitária Armando Salles de Oliveira - Butantã - Caixa Postal 7141 - 05508-901 - São Paulo, SP - Brasil. 